such as the nitro or tertiary butyl groups, retain characteristic sets of frequencies in different compounds. Deformational motions are also sometimes characteristic. For example, the symmetrical deformational frequency of the $\mathrm{CH}_{3}$-group can be used to indicate its presence in polythene; and different types of olefine can be distinguished by differences in some of their deformational vibrations. The latter results can be used to study the cracking of hydrocarbons or the method of polymerization of un. saturated compounds. Thus, when 1.3 butadiene condenses to form buna rubber, the extent of 1.2 or 1.4 addition can be estimated. In polymeric chemistry a variety of problems can be tackled successfully, such as the arrangements within a long chain, or the structure of interpolymers.

Since no two molecules, except a pair of optical isomers, have the same nuclear configuration, the fact that any molecular vibration involves the entire molecule implies that no two molecules will have a completely identical set of vibration frequencies. The infra-red spectrum will therefore be a fingerprint of the molecule. On this basis, many mixtures, sometimes of great complexity and not susceptible to other methods, can be analysed. The method is particularly suitable for isomeric mixtures. Even stereoisomers show different spectra. Analyses of this kind are rapid and require a very small amount of material. Certain technical difficulties still exist, but are rapidly being overcome, and the method has wide applicability in organic chemistry. Accurate measurements on absorption intensities may also lead to more detailed knowledge about the nature of chemical bonds.

\section{THE ANTIQUITY OF MAN IN AUSTRALIA}

\section{By PROF. F. WOOD JONES, F.R.S. University of Manchester}

A

LARGE part of a recent Memoir of the National Museum, Melbourne (No. 13, 1943), is devoted to the question of the authentic antiquity of certain human artefacts and skeletal remains that have been recorded from various parts of Australia over a long series of years. The available evidence in relation to each find is carefully analysed, and a judicial summing up leads, in most cases, to a verdict of 'not proven'.

This new survey has been undertaken by the director of the Museum, Mr. D. J. Mahony, as a consequence of the recent discovery of mineralized human remains near Keilor at the junction of Dry Creek and the Maribyrnong River in the neighbourhood of Melbourne. The skull was unearthed from undisturbed strata $18 \mathrm{ft}$. below the surface. The district in which the find was made shows the presence of three distinct river terraces. The terrace from which the skull was excavated is the highest of the series and is $45 \mathrm{ft}$. above the adjacent river bed, the other terraces being respectively at the $36-\mathrm{ft}$. and $27-\mathrm{ft}$. levels. Mahony's conclusion from a geological survey of the area is that the terraces "represent the eustatic rise of sea level during the Riss-Würm interglacial phase" and that "the skull and the terrace are evidently contemporaneous". The correlation of the European Riss-Würm period with happenings in southern Australia and Tasmania is made in the assurance that "most glaciologists consider that glacial and interglacial phases were contemporaneous in both hemispheres".

The circumstances of the finding of the skull in situ in the undisturbed face of a sand-pit seem to be well authenticated. The skull itself is mineralized and bears every evidence of being contemporary with the stratum from which it was removed. We may therefore claim that the Keilor skull is the first Australian human fragment the geological antiquity of which is definitely guaranteed by the circumstances of its finding and that, in the opinion of competent Australian geologists, it dates from the Riss-Würm interglacial phase of the Pleistocene period. We may consider its geological story as settled, subject only to possible minor differences of opinion among experts concerning the precise age of the deposit in which the skull was found.

The study of the human remains is, however, far from being completed. In the introductory paper by Mr. Mahony, it is said that "Two mineralised human skulls and some other bones were found". The actual finder of the skull mentioned "one fossilised limb bone and several other fragments" as being with the skull. $\mathrm{He}$ adds that "since then five pieces of another skull were found at the same level and about 6 feet distant from the first skull". Only one skull (lacking the mandible) is in the possession of the National Museum, and it is the only specimen dealt with in this publication.

The account of the skull is written by Dr. J. Wunderly and that of the palate and maxillary teeth by Dr. W. Adam. Neither of these accounts can be considered as being definitive descriptions of the characters of the skeletal remains, and it might have been well to limit the account of the skull to a simple statement of its characters and to have refrained from any suggestions as to racial affinities until the rest of the skeletal remains were available for examination. Dr. Wunderly's conclusions concerning the skull are that "it combines Australoid and Tasmanoid characteristics in about equal proportions". Further, he states that "the Australoid and Tasmanoid anatomical characters are consistent with the theory that the Australians had a bi-racial origin, and also with the supplementary theory that Australia was originally peopled by Negritos. The presence of characteristics of the two racial types is more important than their proportional relationship". I find it difficult to understand the meaning of this last statement. Presumably it means that the Australian race as we know it is compounded of two primary races. But if Dr. Wunderly means that these two primary races were what we now know as Australians (Dravidian or Pre-Dravidian Cymotrichi) and Tasmanians (Oceanic Ulotrichi) is not clear, for the peopling of Australia by Negritos (presumably Tasmanians) he relegates to a "supplementary theory". Should he, in fact, mean that the Australian race is compounded of a Pleistocene Australian-Tasmanian mixture, he must be prepared to admit that the Tasmanian race is equally a mixture of the same two elements. For if that is not admitted, explanation is needed as to how, when Australian and Negrito (Tasmanian) had formed a mixed race in continental Australia in Pleistocene times, the Tasmanians, with all their racial characters intact, were present in Tasmania on the arrival of the white man. Only two possible explanations seem to present themselves. The first is that it so happened that the Ulotrichous Negritos who passed from Australia to Tasmania chanced, in 
some extraordinary way, to have avoided this racial admixture with Australians during their occupation of Australia. The second, that the influx of Negritos into Australia was an event altogether separate from their advent into Tasmania: that there were two independent Negrito migrations, one into the mainland that merged its blood with that of the Australians, the other into Tasmania direct and not via continental Australia and so preserving their full Negrito characters. It cannot be claimed that either of these hypotheses tends to clarify the question of the peopling of the Southern Continent.

Concerning the palate, Dr. Adam concludes that "it is more Tasmanoid than Australoid" in certain features. One of these features is that "it is relatively broad like the Tasmanian palate; the Australian palate is relatively narrower". It is unfortunate that of the Tasmanian and Australian palates figured in Plate XI, that of the Australian would seem to be of a considerably higher relative broadness.

The question would seem to arise as to the possibility of any physical anthropologist sorting out the constituent racial elements present in any individual skull. Tables of figures of comparative measurements are impressive; but it would seem that they are incapable of solving the problem. Taking Dr. Wunderly's tables 1 and 2, in which he gives measurements for Australian, Tasmanian, Maori, Marquesan and Hawaiian skulls, it is at once apparent that it cannot be from these that he has drawn the conclusion that the Keilor skull is compounded of Australoid and Tasmanoid characteristics in about equal proportions. If the measurements of the Keilor skull are matched with the measurements given in the tables of the other skulls, it will be found that in fifty-seven instances they come nearest to those of Australians, in thirty to those of Maoris, in twenty. nine to those of Marquesans, in twenty-one to those of Tasmanians and in eighteen to those of Hawaiians. Surely this is a very disconcerting result to be achieved by the refinements of craniometry. On the other hand, it can scarcely have been on the anatomical features of the skull that Dr. Wunderly makes such a very definite statement, for the morphological characters referred to in the communication are quite insufficient for arriving at a dogmatic diagnosis of racial mixture between the Pleistocene ancestors of the present Australian and Tasmanian races. It might be considered among the triumphs of craniology to diagnose with certainty the product of racial mixture between the Australian and the Tasmanian of the historic period. It is a bold claim indeed to be able to recognize an isolated cranium of an individual as being the product of the racial mixture between the Pleistocene ancestors of these two races living (according to the geological report) more than 100,000 years ago.

It is probably the assertions of Wunderly and Adam that have led Mr. Mahony to include the sentence, "The Keilor skull, which combines Tasmanian with Australian characteristics, supports the theory that Tasmanians once occupied the Australian mainland", in his admirable survey of the whole question of the antiquity of man in Australia. From Australia it is postulated that the Tasmanians passed by way of the Bass Straits Islands into Tasmania. Perhaps, therefore, it would be well to point out that, altogether apart from the question of race mixture already mentioned, there are several other difficulties in the way of accepting this hypothesis. If Tasmanians and Australians had inhabited continental
Australia side by side and had fused their races in Pleistocene times, it must be explained how it came about that the Tasmanian when first encountered by the white man had no dog, although the Australian had, even at the dawn of his story, dogs in plenty, for fossil dingo bones occur in Australia. No remains of the dingo, living or fossil, have ever been found in Tasmania or in the Bass Straits Islands; yet it is a historic fact that the Tasmanians eagerly seized on the cur dogs of the white man to assist them in their food quest. How came it that the Tasmanians remained ignorant of such familiar and important cul. tural developments as the use of the throwing stick, the stone-pointed spear, the boomerang and the shield, familiar enough and of widespread use in Australia?

The National Museum and its director are to be congratulated on having placed on record the first really well-authenticated example of human remains, assignable to a definite geological horizon, that has so far been brought to light in Australia. Here we have a genuine human document of first-class importance. The skull is safe in the custody of the National Museum, and it is much to be hoped that all the other human fragments will be placed in its permanent collections. There will be many opportunities for further examinations of the skeletal remains by anthropologists, and meanwhile it would perhaps be better to accept them as permanent documents rather than to assume that the conclusions drawn from their first examination are necessarily the final ones.

\section{COMPETITIVE RUBBER PLANTS*}

\author{
BY G. MARTIN
}

Superintendent of Research, London Advisory Committee for Rubber Research (Ceylon and Malaya)

GAR more plants contain rubber than is generally 4 realized, but. few contain enough to make extraction worth while. For example, the dandelion (Taraxacum officinale) is typical of the plants in Great Britain which, on bruising, yield a latex or milky fluid containing rubber; but the milk contains much more resin than rubber, and the latter only amounts to about 0.2 per cent of the plant.

The Russian dandelion, kok-saghyz, is similar in general appearance to English dandelions, but contains a much higher proportion of rubber, usually about 10 per cent. Experiments on the cultivation of kok-saghyz are being made in Great Britain, under the general direction of the Royal Botanic Gardens, Kew, as well as in other parts of the Empire and the United States, but it will be difficult, for the time being, to spare in Great Britain the tens of thousands of acres of good agricultural land which would be required to produce 1,000 tons of rubber a year, which is only 1 per cent of our imports prior to 1939.

The rubber-bearing plants of Great Britain are few and insignificant compared with those in other parts of the Empire. According to a report of the Imperial Agricultural Research Institute of India, there are in that country 268 species of plants which are stated to contain rubber. A list of rubber-bearing trees, bushes and plants in Africa, recently prepared by

* Substance of a paper read before the Royal Society of Arts on December 14. 